\title{
Greater daily glucose variability and lower time in range assessed with continuous glucose monitoring are associated with greater aortic stiffness: The Maastricht Study
}

\author{
Yuri D. Foreman ${ }^{1,2}$ (D) William P. T. M. van Doorn ${ }^{1,3} \cdot$ Nicolaas C. Schaper $^{1,4,5}$ • Marleen M. J. van Greevenbroek ${ }^{1,2}$. \\ Carla J. H. van der Kallen ${ }^{1,2} \cdot$ Ronald M. A. Henry ${ }^{1,2,6}$ • Annemarie Koster ${ }^{5,7}$ • Simone J. P. M. Eussen ${ }^{1,8}$ • \\ Anke Wesselius $^{9} \cdot$ Koen D. Reesink $^{1,6,10}$. Miranda T. Schram ${ }^{1,2,6}$. Pieter C. Dagnelie ${ }^{1,2}$. Abraham A. Kroon ${ }^{1,2,6}$. \\ Martijn C. G. J. Brouwers ${ }^{1,4}$ • Coen D. A. Stehouwer ${ }^{1,2}$
}

Received: 16 November 2020 / Accepted: 11 March 2021 / Published online: 15 May 2021

(C) The Author(s) 2021

\begin{abstract}
Aims CVD is the main cause of morbidity and mortality in individuals with diabetes. It is currently unclear whether daily glucose variability contributes to CVD. Therefore, we investigated whether glucose variability is associated with arterial measures that are considered important in CVD pathogenesis.

Methods We included participants of The Maastricht Study, an observational population-based cohort, who underwent at least $48 \mathrm{~h}$ of continuous glucose monitoring (CGM) ( $n=853$; age: $59.9 \pm 8.6$ years; $49 \%$ women, $23 \%$ type 2 diabetes). We studied

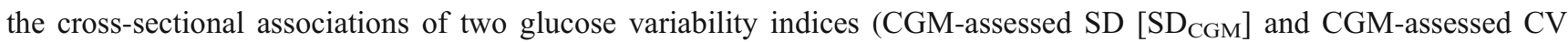
$\left.\left[\mathrm{CV}_{\mathrm{CGM}}\right]\right)$ and time in range $\left(\mathrm{TIR}_{\mathrm{CGM}}\right)$ with carotid-femoral pulse wave velocity (cf-PWV), carotid distensibility coefficient, carotid intima-media thickness, ankle-brachial index and circumferential wall stress via multiple linear regression.

Results Higher $\mathrm{SD}_{\mathrm{CGM}}$ was associated with higher cf-PWV after adjusting for demographics, cardiovascular risk factors and

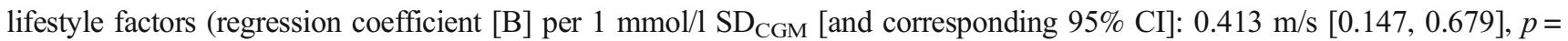
0.002). In the model additionally adjusted for CGM-assessed mean sensor glucose $\left(\mathrm{MSG}_{\mathrm{CGM}}\right), \mathrm{SD}_{\mathrm{CGM}}$ and $\mathrm{MSG}_{\mathrm{CGM}}$ contributed similarly to cf-PWV (respective standardised regression coefficients [st. $\beta \mathrm{s}$ ] and 95\% CIs of 0.065 [ $-0.018,0.167], p=$ 0.160 ; and 0.059 [ $-0.043,0.164], p=0.272)$. In the fully adjusted models, both higher $\mathrm{CV}_{\mathrm{CGM}}(\mathrm{B}[95 \% \mathrm{CI}]$ per $10 \% \mathrm{CV}$ CGM: $0.303 \mathrm{~m} / \mathrm{s}[0.046,0.559], p=0.021)$ and lower TIR $\mathrm{CGM}\left(\mathrm{B}[95 \% \mathrm{CI}]\right.$ per $\left.10 \% \mathrm{TIR}_{\mathrm{CGM}}:-0.145 \mathrm{~m} / \mathrm{s}[-0.252,-0.038] p=0.008\right)$ were statistically significantly associated with higher cf-PWV. Such consistent associations were not observed for the other arterial measures.

Conclusions Our findings show that greater daily glucose variability and lower $\mathrm{TIR}_{\mathrm{CGM}}$ are associated with greater aortic stiffness (cf-PWV) but not with other arterial measures. If corroborated in prospective studies, these results support the development of therapeutic agents that target both daily glucose variability and $\mathrm{TIR}_{\mathrm{CGM}}$ to prevent CVD.
\end{abstract}

Coen D. A. Stehouwer

cda.stehouwer@mumc.nl

1 CARIM School for Cardiovascular Diseases, Maastricht University, Maastricht, the Netherlands

2 Department of Internal Medicine, Maastricht University Medical Centre+, Maastricht, the Netherlands

3 Department of Clinical Chemistry, Central Diagnostic Laboratory, Maastricht University Medical Centre+, Maastricht, the Netherlands

4 Department of Internal Medicine, Division of Endocrinology and Metabolic Disease, Maastricht University Medical Centre+, Maastricht, the Netherlands

5 CAPHRI Care and Public Health Research Institute, Maastricht University, Maastricht, the Netherlands
6 Heart and Vascular Center, Maastricht University Medical Centre+, Maastricht, the Netherlands

7 Department of Social Medicine, Maastricht University, Maastricht, the Netherlands

8 Department of Epidemiology, Maastricht University, Maastricht, the Netherlands

$9 \quad$ NUTRIM School for Nutrition and Translational Research in Metabolism, Department of Complex Genetics and Epidemiology, Maastricht University, Maastricht, the Netherlands

10 Department of Biomedical Engineering, Maastricht University, Maastricht, the Netherlands 


\section{Research in context}

\section{What is already known about this subject?}

- The mechanisms that drive the high risk of CVD in individuals with diabetes and prediabetes are incompletely understood

- A robust body of work supports the concept that mean hyperglycaemia is one of the important determinants of CVD

- Both daily glucose variability and time in range may be independent modifiable risk factors in the pathogenesis of CVD

\section{What is the key question?}

- Are daily glucose variability and time in range, measured with continuous glucose monitoring, associated with several arterial measures that are considered important in the pathogenesis of CVD?

What are the new findings?

- Greater daily glucose variability and lower time in range were associated with higher carotid-femoral pulse wave velocity, which is the gold-standard measure of aortic stiffness and an independent determinant of CVD, cardiovascular mortality and all-cause mortality

- Such independent associations were not observed for the other investigated measures, which included anklebrachial index and carotid intima-media thickness

\section{How might this impact on clinical practice in the foreseeable future?}

- Our findings underscore the independent pathophysiological relevance of daily glucose variability and time in range in the context of macrovascular complications and encourage future studies to assess whether specific targeting of daily glucose variability and time in range can prevent CVD

Keywords Arterial stiffness · Continuous glucose monitoring · Glucose variability · Time in range

\begin{tabular}{|c|c|}
\hline \multicolumn{2}{|c|}{ Abbreviations } \\
\hline AGEs & Advanced glycation end-products \\
\hline ABI & Ankle-brachial index \\
\hline B & Regression coefficient \\
\hline braPP & Brachial pulse pressure \\
\hline carDC & Carotid distensibility coefficient \\
\hline cf-PWV & Carotid-femoral pulse wave velocity \\
\hline cIMT & Carotid intima-media thickness \\
\hline CGM & Continuous glucose monitoring \\
\hline $\mathrm{CV}_{\mathrm{CGM}}$ & CGM-assessed CV \\
\hline $\mathrm{CWS}_{\text {mean }}$ & Mean circumferential wall stress \\
\hline $\mathrm{CWS}_{\text {puls }}$ & Pulsatile circumferential wall stress \\
\hline FPG & Fasting plasma glucose \\
\hline GMS & Glucose metabolism status \\
\hline GV & Glucose variability \\
\hline IAD & Interadventitial diameter \\
\hline LD & Carotid lumen diameter \\
\hline MAP & Mean arterial pressure \\
\hline $\mathrm{MSG}_{\mathrm{CGM}}$ & CGM-assessed mean sensor glucose \\
\hline NGM & Normal glucose metabolism \\
\hline & CGM-assessed standard deviation \\
\hline t. $\beta$ & Standardised regression coefficient \\
\hline
\end{tabular}

TIR $_{\text {CGM }}$ CGM-assessed time in range

VIF Variance inflation factor

\section{Introduction}

CVD is the main cause of morbidity and mortality in individuals with type 2 diabetes [1]. Additionally, individuals with prediabetes are already at an elevated risk of CVD [2]. Hyperglycaemia contributes to this CVD risk, in part, by its adverse effects on arterial stiffness [3-5], atherosclerosis [1, $6]$, and large-artery endothelial function [5, 7]. Accordingly, both achieving and maintaining normoglycaemia are important for reducing CVD risk [1]. However, current treatment modalities have not been able to fully normalise the elevated CVD risk of individuals with type 2 diabetes [1]. A better understanding of the involved pathophysiologic processes could yield new therapeutic targets to further reduce CVD risk.

Glucose variability $(\mathrm{GV})$ is thought to contribute to the development of CVD, irrespective of mean glucose values. Notably, two types of GV need to be distinguished, as they 
are measured differently and represent different underlying aetiologic concepts $[8,9]$. Short-term (or daily) GV reflects actual glucose fluctuations over the day $[9,10]$. By contrast, long-term (or visit-to-visit) GV reflects variance in classic glycaemic indices (e.g., $\mathrm{HbA}_{1 \mathrm{c}}$ ) that have been periodically measured over weeks, months, or years $[8,9]$. While longterm GV may assess daily glucose fluctuations to some extent, it is viewed to largely represent difficult to measure factors that affect glycaemic control (e.g., therapy adherence, multimorbidity, infections) [8]. Whereas multiple studies have shown that long-term GV is independently associated with CVD and all-cause mortality [8, 11-15], the association between daily GV and CVD has only been sparsely investigated [16].

In general, the study of incident CVD requires both a substantial sample size and an ample follow-up period. Large-scale measurement of daily GV with the goldstandard method (i.e., continuous glucose monitoring [CGM]) [17] has been challenging until recently, in part because of costliness and relative invasiveness [18]. Therefore, most studies on this topic have cross-sectionally associated daily GV with measures that reflect the aforementioned processes leading to CVD [19-25]. Importantly, however, these studies either did not adjust for certain important potential confounders [20-23] or assessed daily GV with less precise methods than CGM $[24,25]$.

Hence, we investigated whether daily GV is associated with arterial measures that are considered important in CVD pathogenesis in a population-based cohort study. We studied whether the associations were independent of key demographics, cardiovascular risk factors and lifestyle factors, and assessed to what extent the associations were explained by mean glycaemia. Based on previous work [25], we hypothesised that CGM-derived indices of GV would be most strongly associated with carotid-femoral pulse wave velocity (cf-PWV), which is the gold-standard measure of aortic stiffness because of its independent association with incident CVD, cardiovascular mortality and all-cause mortality [26-28]. In secondary analyses, we assessed the associations of $\mathrm{CV}\left(\mathrm{CV}_{\mathrm{CGM}}\right)$, an index that is intrinsically adjusted for mean glycaemia, and time in range (TIR $\left.\mathrm{TGM}_{\mathrm{C}}\right)$, an emerging glycaemic index that is partly determined by GV [29], with the same arterial outcome variables.

\section{Methods}

Study population and design We used data from The Maastricht Study, an observational, prospective, populationbased cohort study. The rationale and methodology have been described previously [30]. In brief, The Maastricht Study focuses on the aetiology, pathophysiology, complications, and comorbidities of type 2 diabetes, and is characterised by an extensive phenotyping approach. All individuals aged between 40 and 75 years and living in the southern part of the Netherlands were eligible for participation. Participants were recruited through mass media campaigns and from the municipal registries and the regional Diabetes Patient Registry via mailings. For reasons of efficiency, recruitment was stratified according to known type 2 diabetes status, with an oversampling of individuals with type 2 diabetes. In general, the examinations of each participant were performed within a time window of 3 months. The Maastricht Study has been approved by the institutional medical ethical committee (NL31329.068.10) and the Minister of Health, Welfare and Sports of the Netherlands (Permit 131088-105234-PG). All participants gave written informed consent.

Continuous glucose monitoring The rationale and methodology of CGM (iPro2 and Enlite Glucose Sensor; Medtronic, Tolochenaz, Switzerland) have been described previously [31]. From 19 September 2016 to 13 September 2018, all participants were invited to undergo CGM as part of their regular work-up at The Maastricht Study. To accelerate the inclusion process and to ensure inclusion of a sufficient number of participants with prediabetes and type 2 diabetes, we re-invited a selected group of participants who had recently visited The Maastricht Study to undergo CGM as a separate research visit (further referred to as 'catch-up visit'). The CGM device was worn on the lower abdomen and recorded subcutaneous interstitial glucose values (range: $2.2-$ $22.2 \mathrm{mmol} / \mathrm{l}$ ) every $5 \mathrm{~min}$ for a 7 -day period. Participants were asked to self-measure their blood glucose four times daily (Contour Next; Ascensia Diabetes Care, Mijdrecht, the Netherlands) for retrospective CGM calibration. Participants were blinded to the CGM recording, but not to the selfmeasured values. Diabetes medication use was allowed, and no instructions on diet or physical activity were given.

The first $24 \mathrm{~h}$ of CGM were excluded because of insufficient calibration. Next, we excluded individuals with less than $24 \mathrm{~h}$ of recording (less than one data day). Then, we calculated per participant mean sensor glucose $\left(\mathrm{MSG}_{\mathrm{CGM}}\right), \mathrm{SD}_{\mathrm{CGM}}$, $\mathrm{CV}_{\mathrm{CGM}}$ (i.e., $\mathrm{SD}_{\mathrm{CGM}} / \mathrm{MSG}_{\mathrm{CGM}} \times 100 \%$ ) and $\mathrm{TIR}_{\mathrm{CGM}}$ (i.e., $\%$ of time between 3.9 and $10.0 \mathrm{mmol} / \mathrm{l}$ ) using the total recording period. Based on international consensus, we used $\mathrm{SD}_{\mathrm{CGM}}$ and $\mathrm{CV}_{\mathrm{CGM}}$ as indices of GV [17].

Arterial measurements The rationale and methodology of the arterial measurements have been described previously $[25,32$, 33]. We assessed cf-PWV using applanation tonometry (SphygmoCor, Atcor Medical, Sydney, Australia) [26] and used the median of at least three consecutive cf-PWV recordings in our analyses. Because of its established clinical relevance [26-28], cf-PWV was our main outcome measure of interest. 
In addition, we measured the left common carotid artery with the use of an ultrasound scanner equipped with a $7.5 \mathrm{MHz}$ linear probe (MyLab 70, Esaote Europe, Maastricht, the Netherlands) to assess local carotid distension, intima-media thickness (cIMT), and interadventitial diameter (IAD) [34]. We quantified local arterial stiffness by calculating the carotid distensibility coefficient (carDC) according to the following formula: carDC $=\left(2 \times \Delta \mathrm{D} \times \mathrm{IAD}+\Delta \mathrm{D}^{2}\right) /$ (braPP $\times \mathrm{IAD}^{2}$ ), where $\Delta \mathrm{D}=$ distension and braPP $=$ brachial pulse pressure [35]. We defined cIMT as the distance between the lumen-intima and media-adventitia interfaces of the far (posterior) wall [34], and IAD as the distance between the media-adventitia interfaces of the near and far wall. The median carDC, cIMT and IAD of three consecutive measurements were used.

We calculated carotid lumen diameter (LD) according to the following formula [36]: $\mathrm{LD}=\mathrm{IAD}-(2 \times \mathrm{cIMT})$. In parallel with the vascular measurements, we also determined mean heart rate and mean arterial pressure (MAP) every 5 min with an oscillometric device (Accutorr Plus, Datascope, Montvale, NJ, USA). We calculated mean circumferential wall stress $\left(\mathrm{CWS}_{\text {mean }}\right)$ and pulsatile circumferential wall stress $\left(\mathrm{CWS}_{\mathrm{puls}}\right)$ using the Lamé equation as follows: $\mathrm{CWS}$ mean $=[\mathrm{MAP} \times(\mathrm{LD} / 2)] / \mathrm{cIMT}$ and $\mathrm{CWS}_{\text {puls }}=[\mathrm{braPP} \times(\mathrm{LD} / 2)] / \mathrm{cIMT}[32]$.

Last, the Omron VP2000 (Omron, Kyoto, Japan) was used to automatically determine the ankle-brachial index (ABI) based on simultaneous BP measurements at both ankles and upper arms. The left and right $\mathrm{ABI}$ were calculated by dividing the systolic BP measured at the ankle by the highest systolic BP measured at either upper arm. We used the lowest $\mathrm{ABI}$ in our analyses and excluded individuals with an $\mathrm{ABI}$ above 1.4 [37].

Measurement of covariates As described previously [30], we categorised glucose metabolism status (GMS) based on a standardised $2 \mathrm{~h} 75 \mathrm{~g}$ OGTT and the participant's medication use as either normal glucose metabolism (NGM), prediabetes, or type 2 diabetes [38]. Participants who used insulin or had a fasting plasma glucose value above $11.0 \mathrm{mmol} / \mathrm{l} \mathrm{did}$ not undergo the OGTT. In addition, we assessed educational level (low, intermediate, high), moderate-to-vigorous physical activity, smoking status (never, former, current), alcohol use (none, low, high), and history of CVD by questionnaire. We also calculated the Dutch Healthy Diet index sum score, a measure of adherence to the Dutch dietary guidelines 2015 [39] based on a food frequency questionnaire [40]; assessed lipid-modifying, antihypertensive and glucose-lowering medication use as part of a medication interview; measured weight, height and waist circumference during a physical examination; calculated BMI; measured office and $24 \mathrm{~h}$ ambulatory BP; measured $\mathrm{HbA}_{1 \mathrm{c}}$ and lipid profile in fasting venous blood samples; measured albumin excretion in two $24 \mathrm{~h}$ urine collections; and calculated the eGFR based on serum creatinine only, as cystatin $\mathrm{C}$ values were not presently available in this subpopulation.

Statistical analysis Normally distributed data are presented as mean and SD, non-normally distributed data as median and $\mathrm{IQR}$, and categorical data as $n(\%)$. We used multiple linear regression with a complete-case approach to study the associations of daily GV with arterial measures. The crude analyses only included $\mathrm{SD}_{\mathrm{CGM}}$ as a determinant. Model 1 was adjusted for demographics: age, sex and education level. Model 2 was additionally adjusted for cardiovascular risk and lifestyle factors: MAP (in case of cf-PWV, carDC, and $\mathrm{CWS}_{\text {puls }}$ ), office systolic BP (in case of cIMT and ABI), braPP (in case of $\mathrm{CWS}_{\text {mean }}$ ), mean heart rate (in case of cf-PWV and $\mathrm{ABI}$ only), BMI, total-to-HDL-cholesterol levels, smoking status, alcohol use and antihypertensive and lipid-modifying drug use. To study its contribution relative to $\mathrm{SD}_{\mathrm{CGM}}$, the associations were further adjusted for $\mathrm{MSG}_{\mathrm{CGM}}$ in an additional model (i.e., model $2+\mathrm{MSG}_{\mathrm{CGM}}$ ). The main regression results are presented as regression coefficients (B) with corresponding $95 \% \mathrm{CI}$ and $p$ values.

We presumed the reliability of our model $2+\mathrm{MSG}_{\mathrm{CGM}}$ results to be negatively impacted by multicollinearity because of the strong correlation between $\mathrm{SD}_{\mathrm{CGM}}$ and $\mathrm{MSG}_{\mathrm{CGM}}$ (rho = 0.69) [41]. Hence, we additionally performed ridge regression, an L2-regularised form of linear regression (formula provided in the electronic supplementary material [ESM] Methods), which is a valid statistical method to counter a degree of model instability caused by multicollinearity [42]. Ridge regression estimates are computed according to the combination of the residual sum of squares, characteristic of regular linear regression, and predefined penalisation of the coefficients. As such, it slightly biases the regression coefficients and can strongly reduce inflated variances that arise when high levels of multicollinearity are present. We pragmatically chose the level of penalisation based on the lambda $(\lambda)$ required to reduce the variance inflation factor (VIF) of model $2+\mathrm{MSG}_{\mathrm{CGM}}$ back to the VIF of model 2 (or halfway back). The ridge regression results are presented as standardised regression coefficients (st. $\beta$ ) with $95 \%$ CIs and $p$ values. The median st. $\beta$ s (95\% CIs) were estimated with use of resampling (1000 bootstrap).

In secondary analyses, we replaced the main determinant $\mathrm{SD}_{\mathrm{CGM}}$ with $\mathrm{CV}_{\mathrm{CGM}}$ and $\mathrm{TIR}_{\mathrm{CGM}}$. For clarity, the regression coefficients of both indices are presented per $10 \%$ difference instead of per $1 \%$. To further explore the clinical applicability of our results in the context of the International Consensus on $\mathrm{TIR}_{\mathrm{CGM}}$ [43], we repeated the analyses with $\mathrm{TIR}_{\mathrm{CGM}} \geq 70 \%$ (yes/no) as the main determinant. In addition, we investigated whether the associations were modified by sex [44], age [25], or (type 2) diabetes status by adding interaction terms (e.g., $\mathrm{SD}_{\mathrm{CGM}} \times$ sex) to model 2 .

To test the robustness of our main findings, we performed several sensitivity analyses by (1) replacing $\mathrm{MSG}_{\mathrm{CGM}}$ with 
GMS, $\mathrm{HbA}_{1 \mathrm{c}}$ or fasting plasma glucose; (2) adding physical activity and diet as a separate model because many missing values were observed for these confounders (ESM Table 1); (3) adding specific variables (eGFR, urinary albumin excretion, history of (VD) as a separate model since they may introduce overadjustment bias [45]; (4) substituting office systolic BP with ambulatory systolic BP; and (5) excluding individuals with type 1 diabetes, individuals with CGM data gaps, individuals who underwent CGM as part of a 'catch-up visit', or individuals with a suboptimal CGM recording period (i.e., less than two data days) [31]. Last, we also repeated the primary analyses with $\mathrm{MSG}_{\mathrm{CGM}}$ as the main determinant.

We considered a $p$ value of $<0.05$ statistically significant. Statistical analyses were performed with use of the Statistical Package for Social Sciences (version 25.0; IBM, Chicago, Illinois, USA) and the R programming language (version 3.6.1; R Foundation for Statistical Computing, Vienna, Austria) with package glmnet (version 4.0.2).

\section{Results}

Study population characteristics The total CGM study population comprised 853 individuals (age: $59.9 \pm 8.6$ years; $49 \%$ women, 23\% type 2 diabetes). Because outcome and covariate data could not be obtained in all individuals (ESM Fig. 1, ESM Table 1), the number of participants who were included in the different regression analyses varied $(n=643-816)$. Table 1 shows the participant characteristics of the largest sample size (i.e., ABI study population) stratified according to tertiles of $\mathrm{SD}_{\mathrm{CGM}}$. With higher $\mathrm{GV}$, participants were older, more often male, and were generally characterised by a more unfavourable cardiometabolic profile (i.e., higher $\mathrm{HbA}_{1 \mathrm{c}}$, $\mathrm{BP}$ and $\mathrm{BMI}$ values and more often current smoker). GMS did not fully correspond with daily GV. Namely, 31 (17\%) of the 185 individuals with type 2 diabetes were not in the highest tertile of $\mathrm{SD}_{\mathrm{CGM}}$, participants with prediabetes were evenly distributed between the tertiles, and $58(13 \%)$ of the 454 individuals with NGM were not in the lowest or middle tertiles. ESM Table 2 and ESM Figs 2-4 additionally show that the different GMS categories have substantially overlapping $\mathrm{SD}_{\mathrm{CGM}}$ values.

Daily GV and arterial stiffness Figure 1 and ESM Table 3 show the associations of $\mathrm{SD}_{\mathrm{CGM}}$ with cf-PWV and carDC estimated by use of multiple linear regression. Higher $\mathrm{SD}_{\mathrm{CGM}}$ was statistically significantly associated with higher cf-PWV after adjustment for demographics, cardiovascular risk factors and lifestyle factors (model 2, B: $0.413 \mathrm{~m} / \mathrm{s}$ [0.147, 0.679], $p=$ 0.003 ). Although numerically, the regression estimate was attenuated by a third after additional adjustment for $\mathrm{MSG}_{\mathrm{CGM}}$ (model $2+\mathrm{MSG}_{\mathrm{CGM}}$, B: $0.270 \mathrm{~m} / \mathrm{s}[-0.125$, $0.666], p=0.180$ ), the coefficients were not statistically significantly different.
Table 2 shows the fully adjusted st. $\beta$ s of $\mathrm{SD}_{\mathrm{CGM}}$ and $\mathrm{MSG}_{\mathrm{CGM}}$, as estimated with ridge regression, to allow better comparison of the strength of association of both indices with cf-PWV. The coefficients were comparable and both not statistically significant (st. $\beta$ : $0.065[-0.018,0.167], p=0.160$ for $\mathrm{SD}_{\mathrm{CGM}}$; and st. $\beta$ : $0.059[-0.043,0.164], p=0.272$ for $\mathrm{MSG}_{\mathrm{CGM}}$ ).

In the analysis with $\mathrm{CV}_{\mathrm{CGM}}$ as the determinant, the association with cf-PWV was statistically significant after full adjustment (model 2, B per 10\% $\mathrm{CV}_{\mathrm{CGM}}: 0.303 \mathrm{~m} / \mathrm{s}$ [0.046, 0.559], $p=0.021$; ESM Table 4). In line with the main results, higher $\mathrm{TIR}_{\mathrm{CGM}}$ was independently associated with lower cf-PWV (model 2, B per 10\% TIR $\mathrm{CGM}$ : $-0.145 \mathrm{~m} / \mathrm{s}[-0.252,-0.038]$ $p=0.008$; Fig. 1, ESM Table 5). Correspondingly, $\mathrm{TIR}_{\mathrm{CGM}} \geq$ $70 \%$ was independently associated with lower cf-PWV (model 2, B: $-1.098 \mathrm{~m} / \mathrm{s}[-1.745,-0.451], p=0.001$; ESM Table 6).

$\mathrm{SD}_{\mathrm{CGM}}$ was not associated with carDC after adjustment for demographics, cardiovascular risk factors, lifestyle factors, and $\mathrm{MSG}_{\mathrm{CGM}}$ (model $2+\mathrm{MSG}_{\mathrm{CGM}}$, B: $-0.07110^{-3} / \mathrm{kPa}$ [-1.204, 1.063], $p=0.903) . \mathrm{CV}_{\mathrm{CGM}}$ and $\mathrm{TIR}_{\mathrm{CGM}} \geq 70 \%$ were also not associated with carDC (ESM Table 4 and 6). Inconsistently, TIR $_{\mathrm{CGM}}$ was independently associated with carDC (model 2, B per 10\% TIR $\mathrm{CGM}_{\mathrm{M}}$ : $-0.35010^{-3} / \mathrm{kPa}$ $[-0.646,-0.055], p=0.020$; ESM Table 5).

Daily GV and arterial structure Figure 2 and ESM Table 3 show the associations of $\mathrm{SD}_{\mathrm{CGM}}$ with cIMT and $\mathrm{ABI}$. $\mathrm{SD}_{\mathrm{CGM}}$ and cIMT were not associated after adjustment for all potential confounders and $\mathrm{MSG}_{\mathrm{CGM}}$ (model $2+$ $\left.\mathrm{MSG}_{\mathrm{CGM}}, \mathrm{B}:-1.648 \mu \mathrm{m}[-33.984,30.688], p=0.920\right)$. While $\mathrm{CV}_{\mathrm{CGM}}$ and $\mathrm{TIR}_{\mathrm{CGM}}$ were not independently associated with cIMT (ESM Table 4 and 5), $\mathrm{TIR}_{\mathrm{CGM}} \geq 70 \%$ was (model 2: B: -63.722 [-115.422, -12.023], $p=0.016$; ESM Table 6).

Higher $\mathrm{SD}_{\mathrm{CGM}}$ was statistically significantly associated with lower $\mathrm{ABI}$ after adjustment for demographics, but not after further adjustment for cardiovascular risk and lifestyle factors (model 2, B: $-0.011[-0.026,0.003], p=0.126$ ). Adjustment for $\mathrm{MSG}_{\mathrm{CGM}}$ numerically altered the regression coefficient but did not affect statistical significance (model $2+\mathrm{MSG}_{\mathrm{CGM}}, \mathrm{B}:-0.017$ [-0.039, 0.005], $\left.p=0.121\right)$. Although $\mathrm{CV}_{\mathrm{CGM}}$ and $\mathrm{TIR}_{\mathrm{CGM}}$ were not independently associated with ABI (ESM Tables 4 and 5), $\operatorname{TIR}_{\mathrm{CGM}} \geq 70 \%$ was (model 2, B: 0.041 [0.004, 0.077], $p=0.030$; ESM Table 6).

Daily GV and circumferential wall stress After full adjustment, $\mathrm{SD}_{\mathrm{CGM}}$ was not associated with $\mathrm{CWS}_{\text {mean }}$ (model 2, B: $0.077 \mathrm{kPa}[-1.313,1.467], p=0.913$; ESM Table 3 ) or $\mathrm{CWS}_{\text {puls }}$ (model 2, B: $-0.202 \mathrm{kPa}[-1.019,0.614], p=$ 0.627; ESM Table 3). Further adjustment for $\mathrm{MSG}_{\mathrm{CGM}}$ did not materially alter the results. $\mathrm{CV}_{\mathrm{CGM}}$ and TIR $\mathrm{CGM}_{\mathrm{C}}$ were not independently associated with $\mathrm{CWS}_{\text {mean }}$ and $\mathrm{CWS}_{\text {puls }}$ (ESM Tables 4 and 5). 
Table 1 Characteristics of ABI study population $(n=816)$ stratified according to tertiles of $\mathrm{SD}_{\mathrm{CGM}}$

Characteristic

First $\mathrm{SD}_{\mathrm{CGM}}$ tertile: $0.32-0.72 \mathrm{mmol} / 1$

$(n=276)$

$57.8 \pm 8.9$
$147(53.3)$
$63 / 76 / 137$
$22.8 / 27.5 / 49.6$

$230 / 40 / 6 / 0$
$83.3 / 14.5 / 2.2 / 0$
$6(2.2)$
$5.1[4.9-5.5]$
$5.5[4.7-6.9]$
$5.7[5.4-6.0]$
$0.63[0.55-0.68]$
$10.8[9.9-11.7]$
$100.0[100.0-100.0]$

$5.4[5.2-5.5]$

$35.0[33.0-37.0]$

$0(0)$

$0(0)$

$0(0)$

$0(0)$

$0(0)$

$0(0)$

$0(0)$

SGLT-2 inhibitors

Lifestyle factors

BMI, $\mathrm{kg} / \mathrm{m}^{2}$

Waist circumference, $\mathrm{cm}$

Men

Women

Physical activity, h/week

Dutch healthy diet index, (range: $0-150$ )

Alcohol use (none/low/high)

$n$

$\%$

Smoking (never/former/current)

$n$

$\%$

Cardiovascular risk factors

History of CVD

Office systolic BP, $\mathrm{mmHg}$

Office diastolic BP, $\mathrm{mmHg}$

MAP, $\mathrm{mmHg}$

Mean heart rate, beats/min

Antihypertensive medication use, $\mathrm{n}$

$26.1 \pm 3.7$

$98.8 \pm 9.9$

$87.2 \pm 10.7$

$38 / 179 / 59$

$122 / 126 / 28$

$44.2 / 45.7 / 10.1$

41 (14.9)

$129.0 \pm 17.5$

$73.7 \pm 9.8$

$95.5 \pm 10.9$

$58(21.0)$
Second $\mathrm{SD}_{\mathrm{CGM}}$ tertile:

0.73-1.00 mmol/1

$(n=267)$

$59.3 \pm 8.7$

$126(47.2)$

$86 / 80 / 101$

$32.2 / 30.0 / 37.8$

107/71/95

$39.2 / 26.0 / 34.8$

$166 / 76 / 25 / 0$

$58 / 59 / 154 / 2$

$62.2 / 28.5 / 9.4 / 0$

21.2/21.6/56.4/0.7

18 (6.7)

44 (16.1)

5.4 [5.0-5.9]

$6.4[5.2-8.0]$

6.5 [5.4-7.6]

$10.3[7.2-14.5]$

$6.0[5.7-6.3]$

$0.84[0.77-0.93]$

$7.1[6.4-8.1]$

$1.40[1.17-1.86]$

$14.0[13.0-15.3]$

100.0 [99.5-100.0]

19.9 [17.5-23.9]

$94.6[82.1-98.4]$

5.5 [5.4-5.7]

$37.0[35.0-39.0]$

$6(2.2)$

$1(0.4)$

$6(2.2)$

$0(0)$

$0(0)$

$0(0)$

$0(0)$

6.0 [5.6-6.8]

42.0 [38.0-51.0]

96 (35.2)

19 (7.0)

$91(33.3)$

$21(7.7)$

4 (1.5)

$1(0.4)$

$1(0.4)$

$26.7 \pm 3.9$

$28.3 \pm 4.8$

$100.7 \pm 10.6$

$106.3 \pm 12.4$

$90.4 \pm 11.5$

$94.2 \pm 12.8$

12.5 [7.5-19.6]

11.5 [6.8-17.9]

$84.5 \pm 16.2$

$81.3 \pm 14.6$

$36 / 180 / 51$

$69 / 164 / 40$

13.5/67.4/19.1

25.3/60.1/14.7

$100 / 135 / 32$

95/136/42

$37.5 / 50.6 / 12.0$

$34.8 / 49.8 / 15.4$

28 (10.6)

53 (19.4)

$133.3 \pm 17.9$

$137.0 \pm 17.9$

$75.4 \pm 10.4$

$75.9 \pm 10.2$

$96.8 \pm 10.7$

$98.6 \pm 10.7$

$60.3 \pm 8.6$

$63.3 \pm 8.9$

84 (31.5)

142 (52.0) 
Table 1 (continued)

\begin{tabular}{|c|c|c|c|}
\hline Characteristic & $\begin{array}{l}\text { First } \mathrm{SD}_{\mathrm{CGM}} \text { tertile: } \\
0.32-0.72 \mathrm{mmol} / 1 \\
(n=276)\end{array}$ & $\begin{array}{l}\text { Second } \mathrm{SD}_{\mathrm{CGM}} \text { tertile: } \\
0.73-1.00 \mathrm{mmol} / 1 \\
(n=267)\end{array}$ & $\begin{array}{l}\text { Third } \mathrm{SD}_{\mathrm{CGM}} \text { tertile: } \\
1.01-4.81 \mathrm{mmol} / 1 \\
(n=273)\end{array}$ \\
\hline Total-to-HDL-cholesterol ratio & $3.3[2.8-4.3]$ & $3.6[2.9-4.3]$ & $3.6[2.8-4.3]$ \\
\hline Triacylglycerols, mmol/l & $1.2[0.9-1.5]$ & $1.3[0.9-1.7]$ & $1.4[1.0-1.9]$ \\
\hline Lipid-modifying medication use, $\mathrm{n}$ & $31(11.2)$ & $42(15.7)$ & $128(46.9)$ \\
\hline eGFR, $\mathrm{ml} \mathrm{min}-1$ [1.73 $\mathrm{m}]^{-2}$ & $81.8 \pm 13.0$ & $79.8 \pm 13.8$ & $80.0 \pm 10.2$ \\
\hline Albuminuria, $\mathrm{n}$ & $7(2.5)$ & $23(8.6)$ & $33(12.2)$ \\
\hline \multicolumn{4}{|l|}{ Outcome measures } \\
\hline $\mathrm{cf}-\mathrm{PWV}, \mathrm{m} / \mathrm{s}$ & $8.3 \pm 1.8$ & $8.5 \pm 1.9$ & $9.5 \pm 2.5$ \\
\hline $\operatorname{carDC} 10^{-3} / \mathrm{kPa}$ & $16.3 \pm 5.8$ & $16.5 \pm 5.9$ & $14.9 \pm 6.1$ \\
\hline cIMT, $\mu \mathrm{m}$ & $865.6 \pm 144.0$ & $899.2 \pm 152.3$ & $906.7 \pm 160.2$ \\
\hline $\mathrm{ABI}$ & $1.14 \pm 0.10$ & $1.14 \pm 0.10$ & $1.13 \pm 0.12$ \\
\hline $\mathrm{ABI}<0.9, n$ & $6(2.2)$ & $8(3.0)$ & $10(3.7)$ \\
\hline $\mathrm{CWS}_{\text {mean }}, \mathrm{kPa}$ & $43.8[38.1-49.5]$ & $44.0[37.7-49.7]$ & $44.3[37.9-52.1]$ \\
\hline $\mathrm{CWS}_{\text {puls }}, \mathrm{kPa}$ & $21.7[18.6-26.1]$ & $22.5[18.7-26.5]$ & $23.2[19.7-29.1]$ \\
\hline
\end{tabular}

Data are reported as mean $\pm \mathrm{SD}$, median [IQR], or number $(\%)$ as appropriate

Data represent the study population of participants with complete data on determinant, outcome (i.e., $\mathrm{ABI}$ ) and confounders

PreD, prediabetes; T2D, type 2 diabetes; T1D, type 1 diabetes, GLP-1 glucagon-like peptide-1; DPP-4 dipeptidase-4; SGLT2, sodium-glucose cotransporter 2

Interaction analyses ESM Table 7 shows all $P_{\text {interaction }}$ values for the associations between $\mathrm{SD}_{\mathrm{CGM}}$ and the arterial outcome measures. A statistically significant $P_{\text {interaction }}$ for age was only observed for the association between $\mathrm{SD}_{\mathrm{CGM}}$ and cIMT ( $p=$
0.044). The association between $\mathrm{SD}_{\mathrm{CGM}}$ and cIMT was stronger in women (ESM Table 8). Age and type 2 diabetes status did not modify any of the studied associations (ESM Tables 7 and 9). a

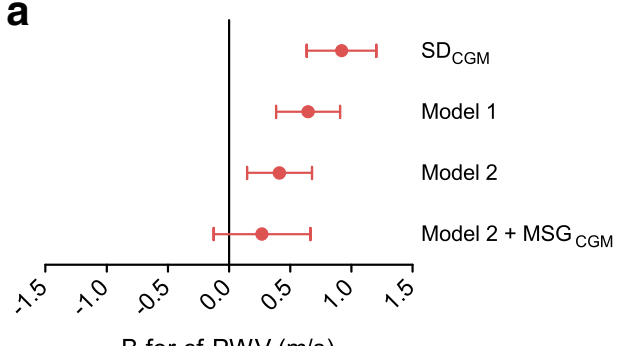

B for cf-PWV $(\mathrm{m} / \mathrm{s})$

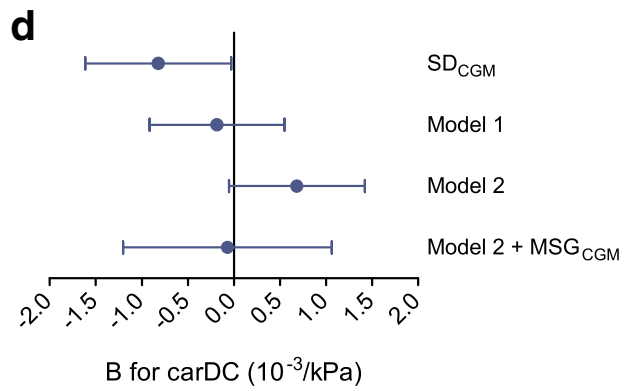

Fig. 1 Multivariable-adjusted associations of $\mathrm{SD}_{\mathrm{CGM}}, \mathrm{CV}_{\mathrm{CGM}}$ and $\mathrm{TIR}_{\mathrm{CGM}}$ with measures of arterial stiffness. Regression coefficients (B) indicate the mean difference $(95 \% \mathrm{CI})$ associated with $1 \mathrm{mmol} / \mathrm{l}$ increase in $\mathrm{SD}_{\mathrm{CGM}}$ or $10 \%$ increase in $\mathrm{CV}_{\mathrm{CGM}}$ or $\mathrm{TIR}_{\mathrm{CGM}}(\mathbf{a}-\mathbf{c})$ Associations with cf-PWV and (d-f) associations with carDC. Model 1: adjusted for

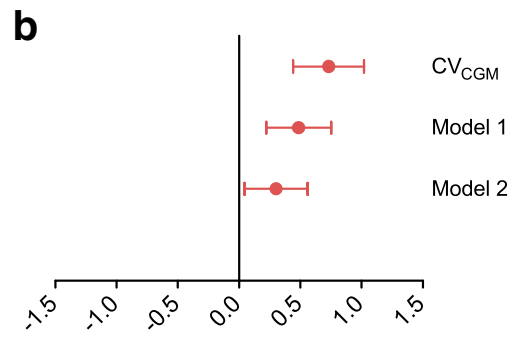

B for cf-PWV (m/s)

e

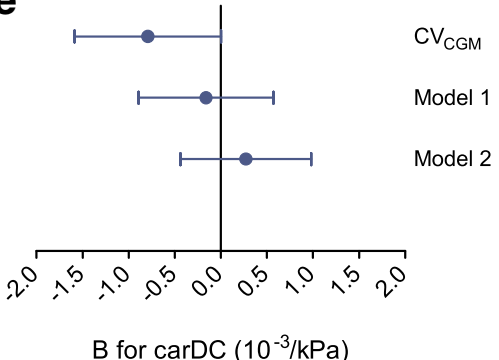

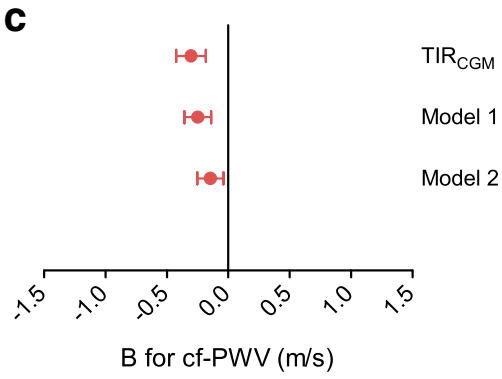

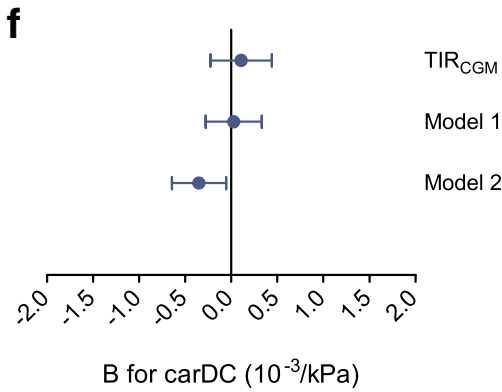

age, sex and education. Model 2: additionally adjusted for MAP, mean heart rate (in the case of cf-PWV only), BMI, smoking status, alcohol use, total-to-HDL-cholesterol levels and use of antihypertensive and lipidmodifying drugs. Model $2+\mathrm{MSG}_{\mathrm{CGM}}$ : additionally adjusted for mean sensor glucose 
Table 2 Standardised regression coefficients of SD and mean sensor glucose in the fully adjusted models with arterial outcome variables

\begin{tabular}{|c|c|c|c|c|c|}
\hline Arterial outcome variable & Ridge regression penalisation $(\lambda)$ & $\mathrm{SD}_{\mathrm{CGM}}(\mathrm{st} . \beta, 95 \% \mathrm{CI})$ & $p$ value & $\operatorname{MSG}_{\mathrm{CGM}}($ st. $\beta, 95 \% \mathrm{CI})$ & $p$ value \\
\hline cf-PWV, SD (n=643) & $\lambda=0.11$ & $0.065(-0.018,0.167)$ & 0.160 & $0.059(-0.043,0.164)$ & 0.272 \\
\hline carDC, $\mathrm{SD}(n=725)$ & $\lambda=0.12$ & $-0.003(-0.097,0.092)$ & 0.952 & $0.088(-0.014,0.184)$ & 0.102 \\
\hline cIMT, SD $(n=726)$ & $\lambda=0.12$ & $-0.007(-0.123,0.111)$ & 0.916 & $0.078(-0.038,0.207)$ & 0.198 \\
\hline ABI, SD $(n=816)$ & $\lambda=0.11$ & $-0.033(-0.071,0.002)$ & 0.060 & $-0.008(-0.032,0.017)$ & 0.548 \\
\hline $\mathrm{CWS}_{\text {mean }}, \mathrm{SD}(\mathrm{n}=725)$ & $\lambda=0.12$ & $-0.059(-0.169,0.066)$ & 0.318 & $0.082(-0.044,0.204)$ & 0.180 \\
\hline $\mathrm{CWS}_{\mathrm{pul}}, \mathrm{SD}(\mathrm{n}=725)$ & $\lambda=0.12$ & $-0.045(-0.145,0.053)$ & 0.374 & $0.042(-0.055,0.138)$ & 0.410 \\
\hline
\end{tabular}

Associations were adjusted for age, sex, educational level, BMI, smoking status, alcohol use, total-to-HDL-cholesterol levels, use of antihypertensive and lipid-modifying drugs, and the other CGM-assessed index. Further, cf-PWV was additionally adjusted for MAP and heart rate; carDC and CWS were additionally adjusted for MAP; cIMT was additionally adjusted for office systolic BP; ABI was additionally adjusted for office systolic BP and heart rate; and $\mathrm{CWS}_{\text {mean }}$ was additionally adjusted for brachial pulse pressure. All coefficients were estimated by use of ridge regression. Point estimates and $95 \%$ CIs were calculated by use of 1000 bootstrap estimates

Standardised regression coefficients (st. $\beta$ ) indicate the median difference $\left(95 \% \mathrm{CI}\right.$ ) associated with $1 \mathrm{SD}$ higher $\mathrm{SD}_{\mathrm{CGM}}$ or $\mathrm{MSG}_{\mathrm{CGM}}$

In the cf-PWV study population, $1 \mathrm{SD}$ corresponds to $0.57 \mathrm{mmol} / 1$ for $\mathrm{SD}_{\mathrm{CGM}}, 1.3 \mathrm{mmol} / \mathrm{l}$ for $\mathrm{MSG}_{\mathrm{CGM}}$, and $2.2 \mathrm{~m} / \mathrm{s}$ for cf-PWV. In the carDC, cIMT, and CWS study populations, $1 \mathrm{SD}$ corresponds to $0.57 \mathrm{mmol} / 1$ for $\mathrm{SD}_{\mathrm{CGM}}, 1.3 \mathrm{mmol} / 1$ for $\mathrm{MSG}_{\mathrm{CGM}}, 6.010^{-3} / \mathrm{kPa}$ for carDC, $152.7 \mu \mathrm{m} \mathrm{for} \mathrm{cIMT}$, $10.2 \mathrm{kPa}$ for $\mathrm{CWS}_{\text {mean }}$, and $6.6 \mathrm{kPa}$ for $\mathrm{CWS}_{\text {puls. }}$. In the $\mathrm{ABI}$ study population, $1 \mathrm{SD}$ corresponds to $0.56 \mathrm{mmol} / 1$ for SD $\mathrm{CGM}, 1.3 \mathrm{mmol} / 1$ for $\mathrm{MSG}_{\mathrm{CGM}}$, and 0.11 for $\mathrm{ABI}$

Additional analyses In general, the main results were not altered by replacement of $\mathrm{MSG}_{\mathrm{CGM}}$ with GMS, $\mathrm{HbA}_{1 \mathrm{c}}$ or fasting plasma glucose (ESM Table 10); additional adjustment for physical activity and diet (ESM Table 11) or for eGFR, urinary albumin excretion, and history of CVD (ESM Table 12); replacement of office systolic BP with ambulatory systolic BP (ESM Table 13); or exclusion of individuals with type 1 diabetes (ESM Table 14). The associations of $\mathrm{SD}_{\mathrm{CGM}}$ with arterial measures were, in general, slightly stronger after exclusion of individuals with CGM data gaps or with a suboptimal CGM recording period (ESM Tables 15 and 16). Exclusion of individuals who underwent CGM as part of a 'catch-up visit' substantially altered the associations between $\mathrm{SD}_{\mathrm{CGM}}$ and the arterial measures (ESM Table 17). ESM Table 18 provides the associations of $\mathrm{MSG}_{\mathrm{CGM}}$ with the arterial measures. Last, ESM Table 19 shows the effects of a
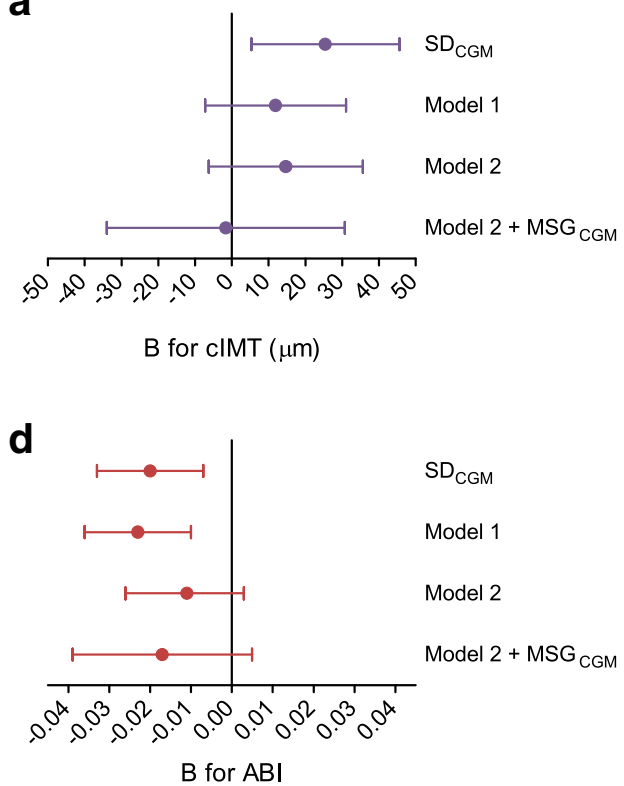

Fig. 2 Multivariable-adjusted associations of $\mathrm{SD}_{\mathrm{CGM}}, \mathrm{CV}_{\mathrm{CGM}}$ and $\mathrm{TIR}_{\mathrm{CGM}}$ with measures of arterial structure. Regression coefficients (B) indicate the mean difference $(95 \% \mathrm{CI})$ associated with $1 \mathrm{mmol} / \mathrm{l}$ increase in $\mathrm{SD}_{\mathrm{CGM}}$ or $10 \%$ increase in $\mathrm{CV}_{\mathrm{CGM}}$ or $\mathrm{TIR}_{\mathrm{CGM}}$. $(\mathbf{a}-\mathbf{c})$ Associations with cIMT and (d-f) associations with ABI. Model 1: adjusted for age, b

e

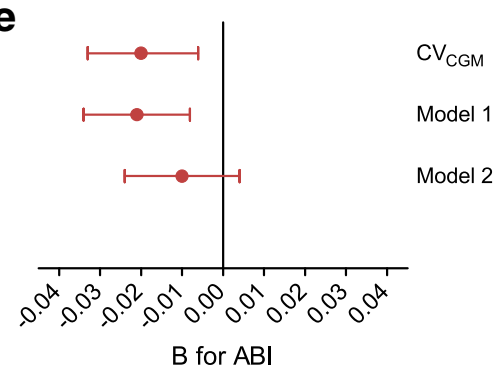

c
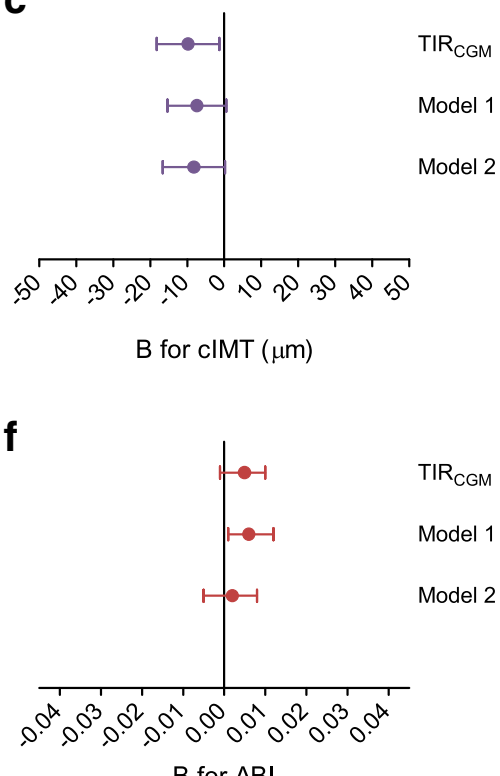

$\mathrm{TIR}_{\mathrm{CGM}}$

Model 1

Model 2

sex and education. Model 2: additionally adjusted for office systolic BP, mean heart rate (in case of ABI only), BMI, smoking status, alcohol use, total-to-HDL-cholesterol levels and use of antihypertensive and lipidmodifying drugs. Model $2+\mathrm{MSG}_{\mathrm{CGM}}$ : additionally adjusted for mean sensor glucose 
different degrees of ridge regression penalisation on the studied associations. In case of ABI, slight regularisation $(\lambda=$ $0.11)$ reversed the st. $\beta$ of $\mathrm{MSG}_{\mathrm{CGM}}$.

\section{Discussion}

In the present study, we investigated the cross-sectional associations of daily GV with several arterial outcome variables in a relatively large population of individuals who underwent more than $48 \mathrm{~h}$ of CGM. Our study has two main findings. First, greater GV was linearly associated with higher cf-PWV, the gold-standard measure to assess aortic stiffness, irrespective of demographics, cardiovascular risk factors and lifestyle factors. The observed association between $\mathrm{SD}_{\mathrm{CGM}}$ and cfPWV was corroborated by our $\mathrm{CV}_{\mathrm{CGM}}$ and $\mathrm{TIR}_{\mathrm{CGM}}$ results. Notably, $\mathrm{SD}_{\mathrm{CGM}}$ and $\mathrm{MSG}_{\mathrm{CGM}}$ contributed to a similar extent to the association with cf-PWV, which suggests an equivalent pathophysiological relevance to aortic stiffness. Second, we established no consistent independent associations between indices of daily $\mathrm{GV}$ and the other investigated arterial measures.

Our main analyses were performed in a study population that comprises the complete spectrum of daily GV (i.e., individuals with NGM, prediabetes, type 2 diabetes and type 1 diabetes). This approach is justified by the substantial overlap in CGM-derived indices between GMS groups, which can be appreciated from ESM Table 2, ESM Figs 2-4, and a recent publication on this cohort [31], and has several advantages over subgroup analyses, such as more statistical power [46] and less range restriction [47]. In addition, because no effect modification by type 2 diabetes status was observed (ESM Table 7), stratification was not indicated. Further, the linearity of the observed associations between daily GV and arterial measures is consistent with work on the 'ticking clock hypothesis', which postulates that hyperglycaemia-induced damage is a continuous process that starts in prediabetes, progresses with the onset of type 2 diabetes, and continues during type 2 diabetes $[48,49]$.

Few studies have investigated the association of CGMmeasured GV with arterial measures [20-22] in concert with sufficient adjustment for potential confounders [19]. Lu et al. did not establish an association of GV with cIMT [19], which is in line with our cIMT results. Recently, we observed that the incremental glucose peak, an OGTT-based proxy of daily GV [31], was statistically significantly associated with higher cfPWV and $\mathrm{CWS}_{\text {mean }}$, but not with carDC, cIMT and $\mathrm{CWS}_{\text {puls }}$ [25]. Notably, our current findings are corroborated by this larger study, as the directions of the regression coefficients generally correspond, and in both instances the strongest association was found with cf-PWV. We presume that discrepancies in statistical significance are largely attributable to the almost threefold sample size differences of our previous
( $n=1849-1978)$ and current study populations $(n=643-$ 816). Although $\mathrm{Lu}$ et al. previously reported on the relation

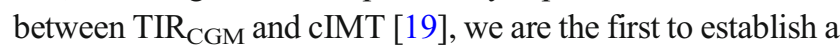
statistically significant association of TIR $\mathrm{CGM}_{\mathrm{C}}$ with cf-PWV.

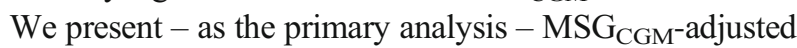
associations with $\mathrm{SD}_{\mathrm{CGM}}$, and - as secondary analyses - associations with the intrinsically $\mathrm{MSG}_{\mathrm{CGM}}$-adjusted index $\mathrm{CV}$ and with TIR $_{\mathrm{CGM}}$, which inversely reflects both mean blood glucose levels and GV [29]. Because they are strongly correlated, it is both necessary and complex to disentangle the effects of glucose fluctuations (i.e., $\mathrm{SD}_{\mathrm{CGM}}$ ) and mean glucose (i.e., $\mathrm{MSG}_{\mathrm{CGM}}$ ) [18]. The strong correlation between $\mathrm{SD}_{\mathrm{CGM}}$ and $\mathrm{MSG}_{\mathrm{CGM}}(\mathrm{rho}=0.69)$, the substantial increase $(121-$ $139 \%$ ) in VIF from model 2 to model $2+\mathrm{MSG}_{\mathrm{CGM}}$ (ESM Table 3), and the opposite directions of the regression coefficients of $\mathrm{SD}_{\mathrm{CGM}}$ and $\mathrm{MSG}_{\mathrm{CGM}}$ (e.g., $\mathrm{ABI}$ ) all indicate multicollinearity [41]. Previous studies on other potential consequences of GV encountered similar contrariety [50, 51], but did not sufficiently address this point. We employed ridge regression to partially counter the potential adverse effects of multicollinearity, thereby allowing for better comparison of $\mathrm{SD}_{\mathrm{CGM}}$ and $\mathrm{MSG}_{\mathrm{CGM}}$ (Table 2). Notably in case of ABI, slight regularisation $(\lambda=0.11)$ reversed the st. $\beta$ of $\mathrm{MSG}_{\mathrm{CGM}}$ (ESM Table 19). Interestingly, the relative contributions of $\mathrm{SD}_{\mathrm{CGM}}$ and $\mathrm{MSG}_{\mathrm{CGM}}$ differed per measure. In the case of cf-PWV, the estimates were similar, which is corroborated by its independent association with $\mathrm{CV}_{\mathrm{CGM}}$ and TIR $_{\text {CGM }}$.

The biological mechanisms that mediate the relationship between GV and aortic stiffness require further elucidation. Several studies observed that greater GV augments inflammation and oxidative stress $[52,53]$. This could promote the formation of advanced glycation end-products (AGEs) [54], which have been suggested to induce arterial stiffening by accumulating in the arterial wall and forming cross-links between elastin and collagen [3-5]. An association of tissue and circulating AGEs has, thus far, only been reported with cfPWV [55, 56], which might explain our contrasting findings for the structurally different aorta (i.e., cf-PWV) and carotid artery (i.e., carDC, cIMT). In addition, cultured human fibroblasts synthesised more collagen during intermittently high glucose concentrations than during stable hyperglycaemia [57]. Higher GV could, thus, lead to higher aortic stiffness by altering the elastin:collagen ratio. Additionally, largeartery endothelial dysfunction may, in part, explain the association between daily GV and cf-PWV [5, 58]. Further, not only higher glucose peaks but also more pronounced glucose nadirs could contribute to CVD development [59]. Recurrent hypoglycaemia has, for example, been shown to negatively affect certain preclinical vascular measures in individuals with type 1 diabetes [60].

Aortic stiffness, assessed via cf-PWV, is an independent determinant of CVD, cardiovascular mortality and all-cause 
mortality [26-28]. We found that cf-PWV was $0.27-0.41 \mathrm{~m} / \mathrm{s}$ higher per $\mathrm{SD}_{\mathrm{CGM}}$ unit $(\mathrm{mmol} / \mathrm{l})$ increase in the final regression models (i.e., model 2 , model $2+\mathrm{MSG}_{\mathrm{CGM}}$ ), which corresponds with 3-4 years of vascular ageing [61]. Hence, the $0.8 \mathrm{mmol} / 1 \mathrm{SD}_{\mathrm{CGM}}$ difference between the first and third $\mathrm{SD}_{\mathrm{CGM}}$ tertile (Table 1) can be translated to a 2- or 3-year vascular ageing difference, which closely matches our recent findings on the OGTT-based incremental glucose peak [25]. Moreover, with every $10 \%$ higher TIR CGM, $_{\text {, }}$-PWV was $0.15 \mathrm{~m} / \mathrm{s}$ lower, which equals minus 18 months of vascular ageing [61]. After full adjustment, a $\operatorname{TIR}_{\mathrm{CGM}} \geq 70 \%$ corresponded to a $1.10 \mathrm{~m} / \mathrm{s}$ lower cf-PWV, an 11-year vascular ageing difference [61]. This statistically significant association remained after further adjustment for $\mathrm{HbA}_{1 \mathrm{c}}(\mathrm{ESM}$ Table 6), which strengthens the recommendations from the International Consensus on TIR $\mathrm{CGM}_{\text {[43]. Prospective studies }}$ should further explore the observed association with aortic stiffness. If confirmative, it would be justified to study whether interventions that specifically target CGM-measured GV or TIR $_{\text {CGM }}$ (e.g., closed-loop insulin delivery systems) can improve CVD risk or incidence [16, 62].

This study has strengths and limitations. Strengths include: (1) the use of the gold-standard methods for daily GV quantification [17]; (2) the use of several, state-of-the-art arterial outcome measures; (3) the extensive participant characterisation, which enabled adjustment for a broad array of possible confounders; (4) the additional use of ridge regression, which allowed us to partly address multicollinearity between $\mathrm{SD}_{\mathrm{CGM}}$ and $\mathrm{MSG}_{\mathrm{CGM}}$; and (5) the robustness of the results, i.e., the overall consistency of several sensitivity analyses, in particular for cf-PWV.

Our study has specific limitations. First, a relatively large number of individuals were excluded because of missing outcome data (ESM Fig. 1). Although the study populations were generally comparable (ESM Table 1), the smaller sample size of the cf-PWV study population negatively impacted statistical power. Second, most of the individuals with diabetes had relatively well-controlled glycaemic indices [31]. The consequent range restriction in the upper $\mathrm{SD}_{\mathrm{CGM}}$ and lower $\mathrm{TIR}_{\mathrm{CGM}}$ spectrum may have biased the regression estimates towards null [47]. Third, the strength of the associations may have been additionally underestimated because of individuals who underwent CGM as a catch-up visit $(n=249 ; 29.2 \%)$ [63], as for these there was a median time of 2.1 years between CGM and the other measurements [31]. While the associations were also investigated in newly recruited individuals only (ESM Table 17), their applicability is substantially hampered by the smaller sample size and different GMS distribution (i.e., lower number of individuals with prediabetes and type 2 diabetes) of the study populations. Fourth, because of the cross-sectional design of our study, we are unable to rule out reverse causality. For example, as greater arterial stiffness has been associated with incident diabetes [64], it could increase GV. Fifth, it could be argued that adjustment for multiple testing would be required in our study [65]. However, we regarded the consequently higher chance of type 2 error undesirable $[65,66]$, especially in the context of a CGM-based study, which commonly has a relatively small sample size because of the costliness and relative invasiveness of CGM [18]. Further, it would be overly strict to enforce adjustment based on the determinants used, since $\mathrm{SD}_{\mathrm{CGM}}, \mathrm{CV}_{\mathrm{CGM}}$ and $\mathrm{TIR}_{\mathrm{CGM}}$ are conceptually and statistically related $[10,29]$. Sixth, our study population is predominately Caucasian, which might limit the generalisability of our results to other populations. Last, although the models were adjusted for many cardiovascular risk and lifestyle factors, residual confounding could still be present.

Our findings support the concept that greater daily GV and

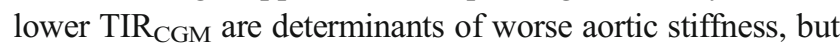
do not support this for other arterial measures. Interestingly, the fully adjusted associations of $\mathrm{SD}_{\mathrm{CGM}}$ and $\mathrm{MSG}_{\mathrm{CGM}}$ with cf-PWV were comparable. Taken together, this study further underscores the pathophysiological relevance of daily GV, irrespective of mean glycaemia, in the context of macrovascular complications. Future studies should explore this association prospectively and assess whether interventions that specifically target CGM-measured GV or TIR $\mathrm{CGM}$ can prevent CVD.

Supplementary Information The online version contains supplementary material available at https://doi.org/10.1007/s00125-021-05474-8.

Acknowledgements The authors are grateful to the participants of The Maastricht Study and to all research personnel involved. In addition, The Regional Association of General Practitioners (Zorg in Ontwikkeling [ZIO]) is gratefully acknowledged for enabling The Maastricht Study to invite individuals with type 2 diabetes based on their electronic health records.

Data availability Data are available from The Maastricht Study for any researcher who meets the criteria for access to confidential data; the corresponding author may be contacted to request data.

Funding The Maastricht Study was supported by the European Regional Development Fund via OP-Zuid, the Province of Limburg, the Dutch Ministry of Economic Affairs (grant 310.041), Stichting De Weijerhorst (Maastricht, the Netherlands), the Pearl String Initiative Diabetes (Amsterdam, the Netherlands), School for Cardiovascular Diseases (CARIM, Maastricht, the Netherlands), School for Public Health and Primary Care (CAPHRI, Maastricht, the Netherlands), School for Nutrition and Translational Research in Metabolism (NUTRIM, Maastricht, the Netherlands), Stichting Annadal (Maastricht, the Netherlands), Health Foundation Limburg (Maastricht, the Netherlands), and by unrestricted grants from Janssen-Cilag B.V. (Tilburg, the Netherlands), Novo Nordisk Farma B.V. (Alphen aan den Rijn, the Netherlands), Sanofi-Aventis Netherlands B.V. (Gouda, the Netherlands), and Medtronic (Tolochenaz, Switzerland). The funders were not involved in the design of the study; the collection, analysis, and interpretation of data; writing the report; and did not impose any restrictions regarding the publication of the report. 
Authors' relationships and activities NCS, RMAH, and MCGJB were supported by Medtronic (External Research Program). Medtronic did not direct design, conduct or outcomes of this study. The authors declare that there are no other relationships or activities that might bias, or be perceived to bias, their work.

Author contributions YDF and MCGJB contributed to conception and design, participated in acquisition of data, analysed and interpreted data, drafted the manuscript, revised the manuscript critically for important intellectual content, and provided final approval of the version to be published. NCS and CDAS contributed to conception and design, contributed to analyses and interpretation of data, revised the manuscript critically for important intellectual content, and provided final approval of the version to be published. WPTMvD analysed data, revised the manuscript critically for important intellectual content, and provided final approval of the version to be published. MMJvG, CJHvdK, RMAH, AK, SJPME, AW, KDR, MTS, PCD, and AAK were involved in the acquisition of data, revised the manuscript critically for important intellectual content and provided final approval of the version to be published. YDF and MCGJB are the guarantors of this work and, as such, had full access to all the data in the study and take responsibility for the integrity of the data and the accuracy of the data analysis.

Open Access This article is licensed under a Creative Commons Attribution 4.0 International License, which permits use, sharing, adaptation, distribution and reproduction in any medium or format, as long as you give appropriate credit to the original author(s) and the source, provide a link to the Creative Commons licence, and indicate if changes were made. The images or other third party material in this article are included in the article's Creative Commons licence, unless indicated otherwise in a credit line to the material. If material is not included in the article's Creative Commons licence and your intended use is not permitted by statutory regulation or exceeds the permitted use, you will need to obtain permission directly from the copyright holder. To view a copy of this licence, visit http://creativecommons.org/licenses/by/4.0/.

\section{References}

1. Low Wang CC, Hess CN, Hiatt WR, Goldfine AB (2016) Clinical update: cardiovascular disease in diabetes mellitus: atherosclerotic cardiovascular disease and heart failure in type 2 diabetes mellitus mechanisms, management, and clinical considerations. Circulation 133 (24):2459-2502. https://doi.org/10.1161/ CIRCULATIONAHA.116.022194

2. Cai X, Zhang Y, Li M et al (2020) Association between prediabetes and risk of all cause mortality and cardiovascular disease: updated meta-analysis. BMJ 370:m2297. https://doi.org/10.1136/bmj. $\mathrm{m} 2297$

3. Stehouwer CD, Henry RM, Ferreira I (2008) Arterial stiffness in diabetes and the metabolic syndrome: a pathway to cardiovascular disease. Diabetologia 51(4):527-539. https://doi.org/10.1007/ s00125-007-0918-3

4. Prenner SB, Chirinos JA (2015) Arterial stiffness in diabetes mellitus. Atherosclerosis 238(2):370-379. https://doi.org/10.1016/ j.atherosclerosis.2014.12.023

5. Zieman SJ, Melenovsky V, Kass DA (2005) Mechanisms, pathophysiology, and therapy of arterial stiffness. Arterioscler Thromb Vasc Biol 25(5):932-943. https://doi.org/10.1161/01.ATV. 0000160548.78317 .29
6. Forbes JM, Cooper ME (2013) Mechanisms of diabetic complications. Physiol Rev 93(1):137-188. https://doi.org/10.1152/physrev. 00045.2011

7. van Sloten TT, Henry RM, Dekker JM et al (2014) Endothelial dysfunction plays a key role in increasing cardiovascular risk in type 2 diabetes: the Hoorn study. Hypertension 64(6):1299-1305. https://doi.org/10.1161/HYPERTENSIONAHA.114.04221

8. Gorst C, Kwok CS, Aslam S et al (2015) Long-term glycemic variability and risk of adverse outcomes: a systematic review and meta-analysis. Diabetes Care 38(12):2354-2369. https://doi.org/10.2337/dc151188

9. Ceriello A, Monnier L, Owens D (2019) Glycaemic variability in diabetes: clinical and therapeutic implications. Lancet Diabetes Endocrinol 7(3):221-230. https://doi.org/10.1016/S2213-8587(18) 30136-0

10. Rodbard D (2018) Glucose variability: a review of clinical applications and research developments. Diabetes Technol Ther 20(S2): S25-S215. https://doi.org/10.1089/dia.2018.0092

11. Bancks MP, Carson AP, Lewis CE et al (2019) Fasting glucose variability in young adulthood and incident diabetes, cardiovascular disease and all-cause mortality. Diabetologia 62(8):1366-1374. https://doi.org/10.1007/s00125-019-4901-6

12. Slieker RC, van der Heijden A, Nijpels G, Elders PJM, t Hart LM, Beulens JWJ (2019) Visit-to-visit variability of glycemia and vascular complications: the Hoorn Diabetes Care System cohort. Cardiovasc Diabetol 18(1):170. https://doi.org/10.1186/s12933019-0975-1

13. Wang A, Liu X, Xu J et al (2017) Visit-to-visit variability of fasting plasma glucose and the risk of cardiovascular disease and all-cause mortality in the general population. J Am Heart Assoc 6(12). https:// doi.org/10.1161/JAHA.117.006757

14. Akirov A, Diker-Cohen T, Masri-Iraqi H, Shimon I (2017) High glucose variability increases mortality risk in hospitalized patients. J Clin Endocrinol Metab 102(7):2230-2241. https://doi.org/10.1210/ jc. $2017-00450$

15. Lee DY, Han K, Park S et al (2020) Glucose variability and the risks of stroke, myocardial infarction, and all-cause mortality in individuals with diabetes: retrospective cohort study. Cardiovasc Diabetol 19(1):144. https://doi.org/10.1186/s12933-020-01134-0

16. Zhou Z, Sun B, Huang S, Zhu C, Bian M (2020) Glycemic variability: adverse clinical outcomes and how to improve it? Cardiovasc Diabetol 19(1):102. https://doi.org/10.1186/s12933020-01085-6

17. Danne T, Nimri R, Battelino T et al (2017) International consensus on use of continuous glucose monitoring. Diabetes Care 40(12): 1631-1640. https://doi.org/10.2337/dc17-1600

18. Rodbard D (2012) The challenges of measuring glycemic variability. J Diabetes Sci Technol 6(3):712-715. https://doi.org/10.1177/ 193229681200600328

19. Lu J, Ma X, Shen Y et al (2019) Time in range is associated with carotid intima-media thickness in type 2 diabetes. Diabetes Technol Ther. https://doi.org/10.1089/dia.2019.0251

20. Su G, Mi S, Tao H et al (2011) Association of glycemic variability and the presence and severity of coronary artery disease in patients with type 2 diabetes. Cardiovasc Diabetol 10:19. https://doi.org/10. 1186/1475-2840-10-19

21. Mo Y, Zhou J, Li M et al (2013) Glycemic variability is associated with subclinical atherosclerosis in Chinese type 2 diabetic patients. Cardiovasc Diabetol 12:15. https://doi.org/10.1186/1475-2840-1215

22. Magri CJ, Mintoff D, Camilleri L, Xuereb RG, Galea J, Fava S (2018) Relationship of hyperglycaemia, hypoglycaemia, and glucose variability to atherosclerotic disease in type 2 diabetes. $\mathrm{J}$ Diabetes Res 2018:7464320. https://doi.org/10.1155/2018/ 7464320 
23. Zhang C, Tang M, Lu X et al (2020) Relationship of ankle-brachial index, vibration perception threshold, and current perception threshold to glycemic variability in type 2 diabetes. Medicine (Baltimore) 99(12):e19374. https://doi.org/10.1097/MD. 0000000000019374

24. Siegelaar SE, Kerr L, Jacober SJ, Devries JH (2011) A decrease in glucose variability does not reduce cardiovascular event rates in type 2 diabetic patients after acute myocardial infarction: a reanalysis of the HEART2D study. Diabetes Care 34(4):855-857. https:// doi.org/10.2337/dc10-1684

25. Foreman YD, Brouwers MCGJ, Berendschot TTJM et al (2019) The oral glucose tolerance test-derived incremental glucose peak is associated with greater arterial stiffness and maladaptive arterial remodeling: The Maastricht Study. Cardiovasc Diabetol 18(1): 152. https://doi.org/10.1186/s12933-019-0950-x

26. Laurent S, Cockcroft J, Van Bortel L et al (2006) Expert consensus document on arterial stiffness: methodological issues and clinical applications. Eur Heart J 27(21):2588-2605. https://doi.org/10. 1093/eurheartj/ehl254

27. Vlachopoulos C, Aznaouridis K, Stefanadis C (2010) Prediction of cardiovascular events and all-cause mortality with arterial stiffness: a systematic review and meta-analysis. J Am Coll Cardiol 55(13): 1318-1327. https://doi.org/10.1016/j.jacc.2009.10.061

28. Sequi-Dominguez I, Cavero-Redondo I, Alvarez-Bueno C, Pozuelo-Carrascosa DP, Nunez de Arenas-Arroyo S, MartinezVizcaino V (2020) Accuracy of pulse wave velocity predicting cardiovascular and all-cause mortality. A systematic review and meta-analysis. J Clin Med 9(7). https://doi.org/10.3390/ jcm9072080

29. Rodbard D (2020) Glucose time in range, time above range, and time below range depend on mean or median glucose or HbAlc, glucose coefficient of variation, and shape of the glucose distribution. Diabetes Technol Ther. https://doi.org/10.1089/dia.2019.0440

30. Schram MT, Sep SJ, van der Kallen CJ et al (2014) The Maastricht Study: an extensive phenotyping study on determinants of type 2 diabetes, its complications and its comorbidities. Eur J Epidemiol 29(6):439-451. https://doi.org/10.1007/s10654-014-9889-0

31. Foreman YD, Brouwers MCGJ, van der Kallen CJH et al (2020) Glucose variability assessed with continuous glucose monitoring: reliability, reference values, and correlations with established glycemic indices-The Maastricht Study. Diabetes Technol Ther 22(5): 395-403. https://doi.org/10.1089/dia.2019.0385

32. Geijselaers SL, Sep SJ, Schram MT et al (2018) Carotid circumferential wall stress is not associated with cognitive performance among individuals in late middle age: The Maastricht Study. Atherosclerosis 276:15-22. https://doi.org/10.1016/j. atherosclerosis.2018.07.003

33. van Sloten TT, Czernichow S, Houben AJ et al (2015) Association between arterial stiffness and skin microvascular function: the SUVIMAX2 study and The Maastricht Study. Am J Hypertens 28(7):868-876. https://doi.org/10.1093/ajh/hpu246

34. Willekes C, Hoeks AP, Bots ML, Brands PJ, Willigers JM, Reneman RS (1999) Evaluation of off-line automated intimamedia thickness detection of the common carotid artery based on M-line signal processing. Ultrasound Med Biol 25(1):57-64. https://doi.org/10.1016/S0301-5629(98)00138-0

35. Reneman RS, Meinders JM, Hoeks AP (2005) Non-invasive ultrasound in arterial wall dynamics in humans: what have we learned and what remains to be solved. Eur Heart J 26(10):960-966. https:// doi.org/10.1093/eurheartj/ehi177

36. Henry RM, Kostense PJ, Dekker JM et al (2004) Carotid arterial remodeling: a maladaptive phenomenon in type 2 diabetes but not in impaired glucose metabolism: the Hoorn study. Stroke 35(3): 671-676. https://doi.org/10.1161/01.STR.0000115752.58601.0B

37. Aboyans V, Criqui MH, Abraham P et al (2012) Measurement and interpretation of the ankle-brachial index: a scientific statement from the American Heart Association. Circulation 126(24):2890 2909. https://doi.org/10.1161/CIR.0b013e318276fbcb

38. WHO (2006) Definition and diagnosis of diabetes mellitus and intermediate hyperglycaemia: report of a WHO/IDF consultation. WHO

39. Looman M, Feskens EJ, de Rijk M et al (2017) Development and evaluation of the Dutch Healthy Diet index 2015. Public Health Nutr 20(13):2289-2299. https://doi.org/10.1017/ S136898001700091X

40. van Dongen MC, Wijckmans-Duysens NEG, den Biggelaar LJ et al (2019) The Maastricht FFQ: development and validation of a comprehensive food frequency questionnaire for the Maastricht study. Nutrition 62:39-46. https://doi.org/10.1016/j.nut.2018.10. 015

41. Vatcheva KP, Lee M, McCormick JB, Rahbar MH (2016) Multicollinearity in regression analyses conducted in epidemiologic studies. Epidemiology (Sunnyvale) 6(2). https://doi.org/10.4172/ 2161-1165.1000227

42. Dormann CF, Elith J, Bacher S et al (2013) Collinearity: a review of methods to deal with it and a simulation study evaluating their performance. Ecography 36(1):27-46. https://doi.org/10.1111/j. 1600-0587.2012.07348.x

43. Battelino T, Danne T, Bergenstal RM et al (2019) Clinical targets for continuous glucose monitoring data interpretation: recommendations from the international consensus on time in range. Diabetes Care 42(8):1593-1603. https://doi.org/10.2337/dci19-0028

44. Schiebinger L, Leopold SS, Miller VM (2016) Editorial policies for sex and gender analysis. Lancet 388(10062):2841-2842. https:// doi.org/10.1016/S0140-6736(16)32392-3

45. Schisterman EF, Cole SR, Platt RW (2009) Overadjustment bias and unnecessary adjustment in epidemiologic studies. Epidemiology 20(4):488-495. https://doi.org/10.1097/EDE. 0b013e3181a819a1

46. Jones SR, Carley S, Harrison M (2003) An introduction to power and sample size estimation. Emerg Med J 20(5):453-458. https:// doi.org/10.1136/emj.20.5.453

47. Bland JM, Altman DG (2011) Correlation in restricted ranges of data. BMJ 342:d556. https://doi.org/10.1136/bmj.d556

48. Haffner SM, Stern MP, Hazuda HP, Mitchell BD, Patterson JK (1990) Cardiovascular risk factors in confirmed prediabetic individuals. Does the clock for coronary heart disease start ticking before the onset of clinical diabetes? JAMA 263(21):2893-2898. https:// doi.org/10.1001/jama.263.21.2893

49. Wong MS, Gu K, Heng D, Chew SK, Chew LS, Tai ES (2003) The Singapore impaired glucose tolerance follow-up study: does the ticking clock go backward as well as forward? Diabetes Care 26(11):3024-3030. https://doi.org/10.2337/diacare.26.11.3024

50. Soupal J, Skrha J Jr, Fajmon M et al (2014) Glycemic variability is higher in type 1 diabetes patients with microvascular complications irrespective of glycemic control. Diabetes Technol Ther 16(4):198203. https://doi.org/10.1089/dia.2013.0205

51. Rizzo MR, Marfella R, Barbieri M et al (2010) Relationships between daily acute glucose fluctuations and cognitive performance among aged type 2 diabetic patients. Diabetes Care 33(10):2169-2174. https://doi.org/10.2337/dc10-0389

52. Ceriello A, Kilpatrick ES (2013) Glycemic variability: both sides of the story. Diabetes Care 36(Suppl 2):S272-S275. https://doi.org/ $10.2337 / \mathrm{dcS} 13-2030$

53. Monnier L, Mas E, Ginet $\mathrm{C}$ et al (2006) Activation of oxidative stress by acute glucose fluctuations compared with sustained chronic hyperglycemia in patients with type 2 diabetes. JAMA 295(14): 1681-1687. https://doi.org/10.1001/jama.295.14.1681

54. Brownlee M (2005) The pathobiology of diabetic complications: a unifying mechanism. Diabetes 54(6):1615-1625. https://doi.org/ 10.2337/diabetes.54.6.1615 
55. van Eupen MG, Schram MT, van Sloten TT et al (2016) Skin autofluorescence and pentosidine are associated with aortic stiffening: The Maastricht Study. Hypertension 68(4):956-963. https:// doi.org/10.1161/HYPERTENSIONAHA.116.07446

56. Baumann M, Richart T, Sollinger D et al (2009) Association between carotid diameter and the advanced glycation end product N-epsilon-carboxymethyllysine (CML). Cardiovasc Diabetol 8:45. https://doi.org/10.1186/1475-2840-8-45

57. Jones SC, Saunders HJ, Qi W, Pollock CA (1999) Intermittent high glucose enhances cell growth and collagen synthesis in cultured human tubulointerstitial cells. Diabetologia 42(9):1113-1119. https://doi.org/10.1007/s001250051279

58. Ceriello A, Esposito K, Piconi L et al (2008) Oscillating glucose is more deleterious to endothelial function and oxidative stress than mean glucose in normal and type 2 diabetic patients. Diabetes 57(5):1349-1354. https://doi.org/10.2337/db08-0063

59. International Hypoglycaemia Study G (2019) Hypoglycaemia, cardiovascular disease, and mortality in diabetes: epidemiology, pathogenesis, and management. Lancet Diabetes Endocrinol 7(5): 385-396. https://doi.org/10.1016/S2213-8587(18)30315-2

60. Gimenez M, Gilabert R, Monteagudo J et al (2011) Repeated episodes of hypoglycemia as a potential aggravating factor for preclinical atherosclerosis in subjects with type 1 diabetes. Diabetes Care 34(1):198-203. https://doi.org/10.2337/dc10-1371
61. McEniery CM, Yasmin, Hall IR et al (2005) Normal vascular aging: differential effects on wave reflection and aortic pulse wave velocity: the Anglo-Cardiff Collaborative Trial (ACCT). J Am Coll Cardiol 46(9):1753-1760. https://doi.org/10.1016/j.jacc.2005.07. 037

62. Ceriello A (2020) Glucose variability and diabetic complications: is it time to treat? Diabetes Care 43(6):1169-1171. https://doi.org/10. 2337/dci20-0012

63. Hutcheon JA, Chiolero A, Hanley JA (2010) Random measurement error and regression dilution bias. BMJ 340:c2289. https://doi.org/ 10.1136/bmj.c2289

64. Muhammad IF, Borne Y, Ostling G et al (2017) Arterial stiffness and incidence of diabetes: a population-based cohort study. Diabetes Care 40(12):1739-1745. https://doi.org/10.2337/dc171071

65. Althouse $\mathrm{AD}$ (2016) Adjust for multiple comparisons? It's not that simple. Ann Thorac Surg 101(5):1644-1645. https://doi.org/10. 1016/j.athoracsur.2015.11.024

66. Rothman KJ (1990) No adjustments are needed for multiple comparisons. Epidemiology 1(1):43-46. https://doi.org/10.1097/ 00001648-199001000-00010

Publisher's note Springer Nature remains neutral with regard to jurisdictional claims in published maps and institutional affiliations. 